\title{
Made in China
}

\author{
Christine A. Haller, MD
}

Melamine-contaminated pet food, lead-containing children's toys, tainted toothpaste and counterfeit drugs have sparked worldwide fear about the safety of consumer products exported from China. Anxious U.S. consumers are increasingly avoiding items that display "Made in China" on the label in light of legitimate safety concerns about a number of exported Chinese products.

China is accused of exporting wheat gluten containing the industrial chemical melamine that was detected in pet food and livestock feed in the United States in 2007. The U.S. Food and Drug Administration (FDA) banned imports of Chinese wheat gluten after the melamine-contaminated ingredient was traced to a single supplier in China and associated with kidney failure and death in many cats and dogs [1].

The Consumer Product Safety Commission announced in June 2007 the recall of several children's items imported from China because of lead contamination. Children's jewelry and toys ranging from sidewalk chalk to toy drums and action figures were found to contain high lead levels. Mattel, the world's largest toy manufacturer, with operating plants in Asia for nearly 50 years, recalled more than 1.5 million toys including Barbie dolls and Hot Wheels cars contaminated with lead-based paint just weeks before the start of the 2007 holiday shopping season [2].

The FDA also issued an alert to consumers to avoid using toothpaste made in China after diethylene glycol-contaminated toothpaste was seized in Costa Rica, Panama, Nicaragua and the Dominican Republic [3]. No serious illnesses were reported from use of the adulterated toothpaste.

The greatest tragedy stemming from the recent wave of contaminated and poor-quality exports from China resulted from shipments of glycerin that were intentionally substituted with diethylene glycol. Forty-six barrels of the toxic substance were exported from eastern China to Hengxiang, Panama and unknowingly blended into 260,000 bottles of cough syrup. There are 100 confirmed deaths, many of them children, with another 265 suspected deaths from ethylene glycol poisoning [4]. At least three trading companies across the globe were involved in the transit of the counterfeit glycerin, none testing the substance, and at least one apparently altered the import certificate to obfuscate its origin. Efforts to identify the source of the tainted material were further hampered by reluctant physicians fearful of litigation, as well as poor labeling and inadequate resources at regulatory agencies on both import and export ends to aid in the investigation.

Toxicologists and historians alike know that this is not the first occurrence of mass poisoning due to diethylene glycol poisoning from a consumer product. The sweet-tasting solvent has been substituted in the past, intentionally or unknowingly, for the innocuous but more costly sweetener, glycerin, in oral medications, foods, and other products, with dire consequences. Diethylene glycol-containing medicines have previously caused mass poisonings in Haiti, Bangladesh, Argentina, and India. Three of the last four such deadly outbreaks have involved products made in China, reputed as a major source of counterfeit drugs.

Adverse health outcomes due to poor-quality products are not limited to exports from China. Many people have died in China because of substandard quality food and drugs. Recent examples include dozens of deaths after taking counterfeit medicines that contained no active ingredients, resulting in inadequate treatment, and 13 infant deaths from malnutrition in 2005 as a result of drinking formula without nutritional value.

It is increasingly clear that China's role as a leading worldwide supplier of consumer goods is not matched by high regulatory standards to ensure quality and safety of its exported products. Response by the Chinese government to bans on several imports and growing global wariness about the safety of Chinese products has been swift and fierce. Most dramatic was the recent execution of the former head of China's state food and drug administration, Zheng Xiaoyu, who was tried and sentenced to death for fraud and corruption for allegedly accepting bribes from firms to register their products without proper evaluation [5]. In August 2007, China announced a massive effort to improve drug safety including a series of regulatory changes, tighter control of manufacturing facilities, and a crackdown on production and sales of drug products. These revisions will create a stricter drug registration and approval process and develop a more efficient system of drug regulation [6]. These reforms are backed by a $\$ 1.7$ billion investment and include establishment of 31 regional centers for surveillance of adverse drug effects.

It is interesting to note that the recent tragedy and subsequent reform of drug regulation in China mirrors events 70 years ago in the United States, when diethylene glycol-contaminated Elixir Sulfanilamide killed more than 100 people. This tragedy led 
to enactment in 1938 of the Federal Food, Drug, and Cosmetic Act, and creation of the modern day FDA that regulates these products [7].

The author has no potential financial conflicts of interest to report.

\section{REFERENCES}

1. FDA's Ongoing Pet Food Investigation. U.S. Food and Drug Administration. April 16, 2007. Available at: http://www.fda.gov/consumer/updates/petfoodrecallup.html. Accessed January 18, 2008.

2. After stumbling, Mattel cracks down in China. New York Times, August 22, 2008. Available at: http://www.nytimes.com/ 2007/08/29/business/worldbusiness/29mattel.html?_r=1\&hp\&oref= slogin. Accessed January 18, 2008.
3. U.S. seizes tainted toothpaste made in China. Reuters, June 1, 2007. Available at: http://www.reuters.com/article/ topNews/idUSWAT00764420070601?feedType=RSS. Accessed January 24, 2008.

4. From China to Panama, a Trail of Poisoned Medicine. New York Times, May 6, 2007. Available at: http://www.nytimes .com/2007/05/06/world/americas/06poison.html. Accessed January 16, 2008.

5. China food safety head executed. $B B C$ News, July 10, 2007. Available at http://news.bbc.co.uk/2/hi/asia-pacific/ 6286698.stm. Accessed April 16, 2008.

6. Chinese legislation to increase drug safety. Royal Society

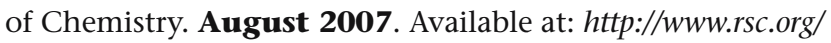
chemistryworld/Issues/2007/August/Chineselegislationtoincreasedrug safety.asp. Accessed January 16, 2008.

7. http://www.fda.gov/oc/history/elixir.html. Accessed January 24, 2008. 